\title{
Avrasya Ekonomik Birliği'ne Siyasi Bakış: Sovyetler Birliği Geri mi Dönüyor? ${ }^{1}$
}

\author{
A Political Glance At Eurasian Economic Union: Is It The Return Of The Soviet \\ Union?
}

\section{Umut BEKCAN 2 a}

a Sorumlu yazar/Responsible author

2 Pamukkale Üniversitesi, İ̈BF, Siyaset Bilimi ve Kamu Yönetimi, ubekcan@pau.edu.tr Orcid ID: 0000-0002-6016-5021

$\begin{array}{ll}\text { Article Info: } & \text { Research Article } \\ \text { Date Submitted: } & 16.03 .2021 \\ \text { Date Revised: } & 02.04 .2021 \\ \text { Date Accepted: } & 08.04 .2021\end{array}$

\section{Abstract}

The Eurasian Economic Union (EEU) is a supranational organization. Its members are Russia, Belarus, Kazakhstan, Armenia, Kyrgyzstan. Whether the EEU has the intention of forming a political union is an important discussion question. There is a "concern" in the West that the Union is an attempt to re-establish the Soviet Union. At this point, as the successor of the Soviet Union and the strongest state in Eurasia politically, militarily and economically, Russia's view of the EEU also gains importance. This study puts this question and its answer at the center.

In the study, firstly the EEU was introduced briefly and its purpose and functions were emphasized. Then, the place and importance of Eurasia and the EEU in Russian foreign policy was mentioned. Finally, an answer was sought to the question of whether the Union was an attempt to re-establish the Soviet Union.

Keywords: Eurasia, Eurasian Economic Union, Russia, Soviet Union, Foreign Policy

JEL codes: F53, F68, N40

$\begin{array}{ll}\text { Makale Bilgisi: } & \text { Araştırma Makalesi } \\ \text { Geliş Tarihi: } & 16.03 .2021 \\ \text { DüzeltmeTarihi: } & 02.04 .2021 \\ \text { Kabul Tarihi: } & 08.04 .2021\end{array}$

Özet

Avrasya Ekonomik Birliği (AEB) ulus üstü bir oluşumdur. Birliğe; Rusya, Belarus, Kazakistan, Ermenistan ve Kırgızistan üyedir. AEB'nin, bir siyasi birlik oluşturma niyeti olup olmadığı önemli bir tartışma sorusudur. Batı'da, Birliğin Sovyetler Birliği'ni yeniden kurma girişimi olduğuna yönelik bir "endişe" vardır. Bu noktada, Sovyetler Birliği'nin ardıl ve Avrasya'da siyasi, askeri ve ekonomik olarak en güçlü devlet olarak Rusya'nın AEB'ye bakışı da önem kazanmaktadır.

$\mathrm{Bu}$ çalışma, bu soruyu ve dolayısıyla cevabını merkeze almıştır. Çalışmada, öncelikle AEB kısaca tanıtılmış, amaç ve işlevleri üzerinde durulmuştur. Ardından Rusya dış politikasında Avrasya'nın ve AEB'nin yeri ve öneminden söz edilmiştir. Son olarak, Birliğin Sovyetler Birliği'ni yeniden kurma girişimi olup olmadığı sorusuna cevap aranmıştır.

Anahtar Kelimeler: Avrasya, Avrasya Ekonomik Birliği, Rusya, Sovyetler Birliği, Dış Politika

JEL kodlarn: F53, F68, N40

\footnotetext{
${ }^{1}$ Yazarlar bu çalışmanın tüm süreçlerinin araştırma ve yayın etiğine uygun olduğunu, etik kurallara ve bilimsel atıf gösterme ilkelerine uyduğunu beyan etmişlerdir. Aksi bir durumda Pamukkale Journal of Eurasian Socioeconomic Studies Dergisi sorumlu değildir. İntihal raporu alınmıștır.

The authors declared that all processes of this study comply with research and publication ethics, and comply with ethical rules and scientific citation principles. Otherwise, Pamukkale Journal of Eurasian Socioeconomic Studies is not responsible. A plagiarism report is received.
} 


\section{EXTENDED SUMMARY}

Research Problem: The Eurasian Economic Union (EEU) is a supranational organization. Its members are Russia, Belarus, Kazakhstan, Armenia, Kyrgyzstan. The Union aims to increase the economic development, modernization and competitiveness of the member states in the world market and to improve the quality of life of the society. For this, it is in an effort to expand the production volume and the domestic market, create new employment, increase income, and create a single market for goods, services, capital and labor resources. The Union has a free trade agreement with Vietnam, Singapore and Serbia, and a trade and economic cooperation agreement with China. In this context, the past, present and future of the EEU, the Eurasian approach, the importance of the EEU in Russian foreign policy constitute are the main problems of this study.

Research Questions: Whether the EEU has the intention of forming a political union is an important discussion question. There is a "concern" in the West that the Union is an attempt to re-establish the Soviet Union. At this point, as the successor of the Soviet Union and the strongest state in Eurasia politically, militarily and economically, Russia's view of the EEU also gains importance. This study puts this question at the center.

Literature Review: It is possible to evaluate the EEU as the first post-USSR economic enterprise with the character of a supranational political institution together with the Customs Union. It can also be thought of as a product of the idea of adding a new dimension to the global trade and economic relations equation, eliminating the excessive dependence of the world economy on the US dollar and creating an independent economy in response to the EU's eastward expansion policy. This makes the EEU the center of attention of the international public opinion politically. While the formation process of the EEU was still continuing in December 2012, the then US Secretary of State Hillary Clinton said that Russia was trying to revive the USSR. She stated that they do not want the region to be Sovietized under the name of the Customs Union or the Eurasian Union, and that they are trying to develop effective ways to slow down or stop the process ("Klinton: SSA ne Dopustyat Vozrojdeniya SSSR", 2012). When the EEU came into force, the Western public perceived this as Russia's move to create a single political and economic space in the territory of the former Soviet Union, "the return to the USSR project". Trying to "save it from Russia" and bring it to the Western camp, the application of economic sanctions on Russia due to the annexation of Crimea were, in a sense, efforts to put a stone in front of this formation in Eurasia. And this study focused on this problem and used official and non-official internet resources, articles and books on Russian foreign policy, Eurasian approach and the EEU in Russian academic literature to prove its claim and they were listed in the references. There are not enough studies in the Turkish literature on this subject in academic article format. This study humbly aims to fill the gap in this regard.

Methodology: The study is discussed from a historical perspective by the notion that the subject of history is unique, in the Traditional Approach of International Relations. In the study, firstly the EEU was introduced briefly and its purpose and functions were emphasized. Then, the place and importance of Eurasia and the EEU in Russian foreign policy was mentioned. Finally, an answer was sought to the question of whether the Union was an attempt to re-establish the Soviet Union. 
Results and Conclusions: The EEU is one of the unions established on the basis of the customs union and free trade area currently in effect in the world. The EEU should be evaluated in the same way that economic unity is evaluated in any region of the world. There are many economic unions in the international arena. Probably none of them has the experience and affinity of the peoples of Eurasia in the past. The Eurasian region is a geography where countries that have lived together for a long time and have a common history, language, culture and traditions. In this context, the establishment of the EEU is a perfectly normal development and should come as no surprise to anyone. But it attracts more attention economically and politically than its counterparts in the international arena. There are three reasons for this. The first is that the EEU uses the concept of Eurasia and has the mentality of Eurasianism. The second is that one of its members is Russia, which has not historically gotten along with the Western world (especially in roughly the last 100 years). Third, the Eurasian region is located within the political and economic expansion area of the West. In accordance with the Eurasian approach, Russia is building a wall against the influence of the West in the region; It wants to consolidate its position in the global world as a great, respected and powerful state. The West is not satisfied with the existence of the EEU. It does not want Russia to establish friendships with other countries in its region and to be influential/influenced politically/economically. It considers the Union as the return of the USSR, and even desires such a perception in the Eurasian region. Thus, the West expects the bourgeois classes and anti-Soviet liberals in the countries of the region to adopt an attitude that will negatively affect the development of the EEU. The EEU, on the other hand, while trying to create a space independent from the influence of the USA and the EU, does not do this with slogans of hostility towards the West, on the contrary, it emphasizes that it is open to cooperation with them. 


\section{GíRíș}

Avrasya Ekonomik Birliği'ne (AEB/Birlik) giden sürecin fikri temeli 29 Mart 1994'te dönemin Kazakistan Cumhurbaşkanı Nursultan Nazarbayev tarafından Moskova Devlet Üniversitesi'nde yaptığı konuşmada atıldı. 20 Ocak 1995'te Rusya, Belarus ve Kazakistan gümrük birliği kurulması konusunda uzlaşmaya vardı. 29 Mart 1996'da Rusya, Belarus, Kazakistan ve Kırgızistan ekonomik ve insani alanlarda entegrasyonu derinleştirmeye karar verdiler. 26 Şubat 1999'da Rusya, Belarus, Kazakistan, Kırgızistan ve Tacikistan ilk Gümrük Birliği Antlaşmasını imzaladı, ancak bir buçuk yıl sonra gümrük birliği üyelerinin bileşimi anlaşmazlıklar nedeniyle değişti. 10 Ekim 2000’de Belarus, Kazakistan, Kırgızistan, Rusya ve Tacikistan tarafından Avrasya Ekonomik Topluluğunun (AET) kurulmasına ilişkin antlaşma imzalandı ve ilk ulus üstü organ olarak AET Mahkemesi oluşturuldu. 30 Mayıs 2001'de söz konusu anlaşma yürürlüğe girdi ve gümrük birliğinin yerini aldı. 19 Eylül 2003'te Rusya, Belarus, Kazakistan ve Ukrayna arasında ortak ekonomik alanın oluşturulmasına ilişkin anlaşma imzalandı fakat Ukrayna bu anlaşmayı onaylamadı. Tacikistan ve Ukrayna'dan farklı olarak süreci 1srarla devam ettiren Rusya, Belarus ve Kazakistan 6 Ekim 2007' de tek bir gümrük bölgesi ve birliği üzerinde anlaşmaya vardı. 9 Aralık 2010'da aynı ülkeler tek bir gümrük bölgesi oluşturulmasıyla ilgili 17 belge imzaladı. 1 Ocak 2012' de bu ülkeler arasında ortak pazar oluşturuldu. 29 Mayıs 2014'te Avrasya Ekonomik Birliği'nin kurulmasına ilişkin anlaşma imzalandı. 10 Ekim'de Ermenistan, 23 Aralık'ta Kırgızistan bu anlaşmaya katıldı. Anlaşma 1 Ocak 2015'te yürürlüğe girdi ve Avrasya Ekonomik Birliği kurulmuş oldu. Birlik; malların, sermayenin, hizmetlerin ve emeğin serbest dolaşımını amaçlıyordu. Üye devletler arasında endüstri, tarım, finans, ulaşım, ticaret ve enerji politikalarının koordinasyonunun sağlanması da hedefleniyordu².

AEB, Avrupa Birliği (AB) benzeri bir ulus üstü yapılanma öngördüğünden dolayı Birliğin $A B^{\prime}$ nin henüz başaramadığı bir siyasi birlik oluşturma niyeti olup olmadığı akla gelen önemli bir sorudur. Bir anlamda bu, birleşik bir devlet kurmayı gündeme getirmektedir. Bu coğrafyada Aralık 1991'e kadar Sovyetler Birliği'nin (SSCB/Sovyetler) var olduğu hatırlanınca soru “acaba Sovyetler Birliği geri mi dönüyor, yeniden mi kuruluyor?" şekline dönüşmektedir. Bu noktada, Sovyetler Birliği'nin ardılı, en büyük varisi ve Avrasya'da siyasi, askeri ve ekonomik olarak en güçlü devlet olarak Rusya'nın AEB'ye bakışı da önem kazanmaktadir.

$\mathrm{Bu}$ çalışma, bu soruyu ve dolayısıyla cevabını merkeze almıştır. Öncelikle AEB kısaca tanıtılmış, amaç ve işlevleri üzerinde durulmuş, ardından Rusya dış politikasında Avrasya'nın ve AEB'nin yeri ve öneminden söz edilmiş, son olarak birliğin SSCB'yi yeniden kurma girişimi olup olmadığı sorusuna cevap aranmıştır.

\section{BİR EKONOMIKK BÜTÜNLEŞME DENEMESI OLARAK AVRASYA EKONOMİK BİRLİĞí}

AEB'yi, öncesinde Gümrük Birliği'yle beraber SSCB sonrası ilk ulus üstü bir siyasi kurum karakterine sahip ekonomik girişim olarak değerlendirmek mümkündür (Vinokurov vd., 2017: 27). Küresel ticari ve ekonomik ilişkiler denklemine yeni bir boyut kazandırma, dünya ekonomisinin $\mathrm{ABD}$ dolarına aşırı bağımlılığını ortadan kaldırma ve AB'nin doğuya

\footnotetext{
${ }^{2}$ Kuruluş sürecinin tüm gelişmelerini, yayınlanan deklarasyonları, imzalanan anlaşma belgelerini ayrıntılı olarak bkz: (“Hronologiya Razvitiya”, 2021).
} 
genişleme politikasına cevaben bağımsız bir ekonomi yaratma düşüncesinin bir ürünü olduğu da düşünülebilir. Bu, AEB'yi siyasi olarak da uluslararası kamuoyunun ilgi odağı haline getirmektedir ("Yevraziyskiy Ekonomiçeskiy Soyuz: Vozvraşçeniye k SSSR?”, 2015). Birliğe Rusya, Belarus, Kazakistan, Ermenistan ve Kırgızistan üye devletlerdir. Moldova, Özbekistan ve Küba gözlemci statüsündedir. Yüksek Avrasya Ekonomik Konseyi, üye devletlerinin başkanlarını içeren Birliğin en üst organıdır. Avrasya Hükümetlerarası Ekonomik Konseyi, üye devletlerin hükümet başkanlarını içeren bir organdır. Avrasya Ekonomik Komisyonu, AEB'nin ve gümrük birliğinin ulus üstü düzenleyici organıdır. Komisyonun temel görevleri, Birliğin işleyişi ve gelişmesi için gerekli koşulların sağlanması ve Birlik içinde ekonomik entegrasyon alanında tekliflerin geliştirilmesidir. Birlik Mahkemesi, AEB Antlaşması ve Birlik içindeki diğer uluslararası antlaşmaların üye devletler ve Birlik organları tarafından uygulanmasını sağlayan yargı organıdır ("Organı Upravleniya", 2021).

Birlik, üye devletlerin ekonomik gelişimini, modernizasyonunu ve dünya pazarındaki rekabet gücünün artırılmasını ve toplumun yaşam kalitesini yükseltmeyi amaçlamaktadır. Bunun için üretim hacminin ve iç pazarın genişletilmesi, yeni istihdam yaratma, gelir artışının sağlanması, mal, hizmet, sermaye ve işgücü kaynakları için tek bir pazar oluşturma çabası içerisindedir. AEB ülkelerinin 2020 yılı itibariyle satın alma gücü paritesindeki gayri safi yurtiçi hasıla hacmi 2 milyar 150 milyon dolardır ve nüfusu 186 milyondur. Yüzölçümü ise 20 milyon $\mathrm{km} 2$ 'den fazladır ve yeryüzü topraklarının \% 14'üne tekabül eder. Birliğin Vietnam, Singapur ve Sırbistan'la serbest ticaret anlaşması, Çin ile ticaret ve ekonomik işbirliği anlaşması vardır (Apokin, 2021).

Aralık 2020'de Yüksek Avrasya Ekonomik Konseyi'nde, Birliğin 2025 yılına kadar gerçekleştirmeyi planladığı stratejik hedefler belirlenmiştir. $\mathrm{Bu}$ hedefleri şu şekilde özetleyerek sıralamak mümkündür: (Vısşiy Yevraziyskiy Ekonomiçeskiy Sovet, 2020).

-Mallar, hizmetler, sermaye ve emek için ortak bir pazar oluşumunun tamamlanması

-AEB ortak pazarının etkinliğini artırmak

-Niteliksel olarak daha yüksek bir gümrük yönetmeliği ve idaresine geçiş

-Malların kalitesi ve güvenliğinin garantisini sağlamak

-AEB dijital alanının oluşturulması

-Ekonomik kalkınmaya yönelik mekanizmaların oluşturulması

-Ortak işbirliği projeleri için bir yönetim sistemi oluşturmak, yüksek performanslı sektörler geliştirmek

-Bilimsel ve teknolojik ilerlemeyi teşvik etmek

-AEB kurumlarının verimliliğini artırmak

-Ekonomik işbirliğini, eğitim, sağlık, turizm ve spor alanlarında genişletmek

-AEB'yi gelişen dünyanın en önemli merkezlerinden biri haline getirmek

AEB, bu hedefleri gerçekleştirdiği takdirde kuşkusuz dünya ekonomisinde çok etkili bir güç merkezi olacağı aşikardır. Bununla birlikte Birliğin geldiği aşama, işlevsel olarak ne ölçüde 
başarılı olduğu, ne gibi sorunlar yaşadığı bu çalışmanın sınırlarını aşmaktadır. Şu aşamada AEB'nin ekonomik bütünleşme yeteneğini $A B$ ile kıyaslamanın doğru olmadığını, optimal bir kıyaslamanın NAFTA (Kuzey Amerikan Serbest Ticaret Anlaşması), MERCOSUR (Güney Amerika Ortak Pazarı), ASEAN (Güneydoğu Asya Uluslar Birliği) gibi oluşumlarla yapılabileceği söylenebilir. (Vinokurov vd., 2017: 11-12). Bunun dışında, AEB siyasi açıdan Avrasya/Avrasyacılık temelinde ve özellikle Rusya dış politikası bağlamında incelenen ve tartışılan önemli bir oluşumdur.

\section{RUSYA DIŞ POLITTIKASINDA AVRASYACILIK ve AVRASYA EKONOMİK BİRLİĞí}

Rusya'nın AEB'ye bakışını ve dış politikasındaki yeri ve önemini incelemeden önce Avrasya ve Avrasyacılık kavramlarına değinmek gerekir. Zira bu, bölgeyi ve Rusya'nın uluslararası ilişkilerini anlamak açısından elzemdir. Avrasya, kabaca, eski Sovyet coğrafyası ile Türkiye'den Hindistan'a kadar olan bölgeyi içine alır. Bu çalışmanın konusunu ilgilendiren günümüz Yeni Avrasyacılık anlayışının temelini oluşturan Klasik Avrasyacılık anlayışı 1920'lerde ortaya çıkmıştır. Rusya ve Avrasya'nın ayrı bir kültür olduğu, bu bölgede yaşayan halkların çok etnili (multi-ethnic) bir ulus meydana getirdiği ve Roma-Germen dünyasının düşman olduğu fikrini savunur. (Tolz, 1998: 272; Dugin, 2002: 5-9). Yeni Avrasyacılık SSCB'nin yıkılışı sonrası ortaya çıkmıştır. Protestan ahlakın liberal ekonomi modeline, ürettiği düşüncelere ve bu bağlamda ABD'nin öncülügünü yaptığı Atlantik medeniyetine karşı duruşu içermektedir. 1990'lı yıllarda Rusya'daki dönüşümden ve getirdiği siyasal, ekonomik ve toplumsal sonuçlardan memnun olmayanlar, ABD ve Batı Avrupa'nın eski Sovyet coğrafyasında hegemonya kurmaya çalıştığını ve bunun önlenmesini gerektiğini düşünenler Avrasyacı yaklaşımı desteklemiştir (Dugin, 2003: 239245; Dugin, 2002: 9-15; Bekcan, 2013. 43-44). Avrasyacılık, bir anlamda anti-Amerikanc1lıtır. Tek kutupluluğa ve ABD politikalarına karşı direnmek Amerikan emperyalistlerin haricinde tüm ülkelerin evrensel çıkarınadır ve Avrasyacılık da dünya medeniyetinin Batı kesimi hariç dünyayı temsil eden evrensel bir projedir. Sadece Rusya'nın gelişimi için bir proje değildir, Rusya sınırlarını aşan yeryüzünün tüm insanları için ortak bir projedir (Bassin, 2011: 130131). Bu görüşleri savunan Aleksandr Dugin'in Rusya Devlet Başkanı Vladimir Putin'in danışmanı olması Rus dış politikasında Avrasyacı anlayışın etkisi hakkında epey fikir vermektedir.

AEB'nin kuruluş süreci 1990'lı yıllarda başlasa da ete kemiğe bürünmesi 2000'li yıllarda gerçekleşti. Avrasyacı bakış da böyle bir oluşumu mümkün kılıyordu. Rusya, dış politikada Sovyet sonrası dönemde epey zayıf bir dönem geçirdi ve Putin'le birlikte yeniden ayağa kalkmak, SSCB döneminde olduğu gibi güçlü olmak istedi. Bunun için öncelikle bölgesinde (yakın çevresinde) hakimiyetini sağlamalıydı. Batı'nın yayılmacılığına ve müdahaleciliğine, eski Sovyet coğrafyasında renkli devrimler adı altında ABD yanlısı yönetimlerin iktidara gelmesine karşıydı. Tarihsel olarak Rusya ve öncesinde SSCB kendini hep Batı'nın baskısı ve tehdidi altında hissetti. 1917 Sovyet/Bolşevik Devrimi'yle beraber uluslararası alandan dışlandı, yalnız kaldı. Batılı burjuva devletleri Rusya'da bir işçi sınıfı iktidarını kabullenemediler ve kendi iktidarları için bir tehdit olarak gördüler. II. Dünya Savaşı'nda Nazi Almanya'sı tarafından uzun süre işgal edildi. Büyük bir kurtuluş mücadelesi sonunda 20 milyondan fazla insanını kaybetmesi pahasına bir zafer elde etti. Yalnızlığını ve tabii ki güvenliğini Nazi işgalinden kurtardığı Doğu Avrupa halkları ve sosyalist devletleriyle gidermeye ve sağlamaya çalıştı. Komintern (Komünist Enternasyonal), Kominform 
(Komünist ve İşçi Partileri Enformasyon Bürosu) ve Varşova Paktı gibi siyasi/askeri oluşumların yanında Comecon (Karşılıklı Ekonomik Yardımlaşma Konseyi) gibi ekonomik birlikler kurdu. Gelinen noktada başta SSCB olmak üzere hepsi dağıldı. Birçoğu düşman kamplara NATO'ya (Kuzey Atlantik Antlaşması Örgütü), AB'ye girdi. Örneğin din, dil ve kültür ve ideoloji yakınlığıyla Rusya İmparatorluğu ve sonrasında SSCB'nin en sadık müttefiki olan ve 1980 'lerde SSCB'ye 16. birlik cumhuriyeti olarak katılmayı bile isteyen Bulgaristan hem NATO hem AB üyesi oldu. Sonrasında oluşturulan BDT (Bağımsız Devletler Topluluğu) işlevsiz kaldı. Rusya'nın Batı'dan gelen tazyike karşı kendi refahı ve güvenliği için bölgesinde iyi, güvenilir hatta aynı dili konuşan dostlara ihtiyacı vardı. SSCB sonrası bölgedeki dağılma süreçlerini durdurup tersine çevirmek zorundaydı (Butorina \& Zaharov, 2014).

1990'ların dağılma travması atlatıldıktan sonra 2000'li yıllarla birlikte silkinip yeniden ayağa kalkma sürecine giren Rusya için AEB' nin siyasi bir işlevi olmadığı düşünülemez. Rusya için bu siyasi işlevin anlamı bölgesine hakim olmak böylece Batı etkisini sınırlamak, bölgesini Batı'ya karşı korumak, savunmaktır. Batılılar bunu, Rusya'nın kendi yakın çevresinde hegemonya kurmak istediği şeklinde yorumlama eğilimindedir. Ama Mearsheimer'in de belirttiği gibi Eğer Rusya, ABD'nin sınır komşuları Meksika veya Kanada'yla bir askeri ittifak kurmaya kalksa ABD buna hoşgörüyle yaklaşmayacağı için (Schaffner, 2019) Rusya'nın NATO ve AB yayılmacılığına karşı duruşunu bölgede hegemonya kurmaya çalıştığ1 veya saldırgan bir politika güttüğ̈̈ şeklinde değerlendirmek doğru olmaz. Bu bağlamda Rusya'nın AEB'yi bölgede ekonomik işbirliği ve bütünleşme temeli üzerinde ABD ve $A B$ etkisine/yayılmasına karşı siyasi bir direnç birliği olarak algıladığı söylenebilir (Butorina \& Zaharov, 2014). Bu, Avrasyacı yaklaşımın söylemleriyle de uyumludur. Bütün bunların yanında AEB'nin AB'ye karşı düşmanca bir söylem içerisinde olduğu da iddia edilemez. Ama $A B^{\prime}$ den farklı, yeni, bağımsız bir alan yaratıp $A B$ ile eşit şartlarda bir ekonomik ve ticari ilişki kurmak istediği iddia edilebilir. Örneğin, Avrasya Ekonomik Komisyonu'nun raporuna göre, 2016 yılında AEB üyesi Rusya, Belarus, Kazakistan, Ermenistan ve Kırgızistan'ın $A B$ ülkelerine ihracatı, toplam gerçekleştirdikleri ihracatın yarısını, AB ülkelerinden ithalatı ise toplam ithalatlarının \% 40'1nı oluşturmuştur (Mamırbayeva, 2017). Aynı yıl Rusya Dışişleri Bakanı Sergey Lavrov, Rusya Federal Alt Meclisi, Duma'da yaptığı konuşmada gelecekte, Atlantik'ten Pasifik'e kadar ortak bir ekonomik ve insani alan yaratma fikrinden söz etmiştir (Tsoy, 2016).

Rusya, AEB gibi bir entegrasyon içinde yer almanın hatta lider bir rol oynamanın büyük ve güçlü bir devlet olmak için gerekli olduğunu, daha önce bir arada yaşamış olmanın getirdiği tecrübenin Birliğin başarısı için son derece faydalı olabileceğini düşünmektedir. Ama bunu Moskova'nın emperyal hırs peşinde koştuğu ve herkes için her şeye karar verdiği şeklinde yorumlamak doğru olmaz (Mamırbayeva, 2017). AEB organları fikir birliği içinde karar alan ulus üstü bir niteliğe sahiptir. Entegrasyonun işleyişi ve gelişmesi konusunda faaliyet gösteren Yüksek Avrasya Ekonomik Konseyi'nde her üye devlet iki uzman tarafından temsil edilir, tüm konular oylamaya sunulur ve başkanlık sırayla el değiştirir. Uzmanlar, zaman zaman entegrasyon sürecini olumsuz etkileyebilecek derecede kendi çıkarlarını katı bir şekilde savunmuşlardır (Mamırbayeva, 2017). Örneğin Aralık 2016'da Kırgızistan, Gümrük Kanunu'nu ilk başta imzalamak istememiş, pürüzler giderildikten sonra uzlaşma sağlanmıştır ("Kirgiziya ne Podpisala Zayavleniye o Razvitii Torgovli v YAES", 2016). Rusya 
Devlet Başkanı Vladimir Putin, devletler arası ilişkilerde ideali yakalamanın zor olduğunu, daha eski ve köklü bir örgüt olarak $A B^{\prime}$ de de birçok güçlüklerin ortaya çıtığına işaret ederek, ulaşılan çözümlerin bir uzlaşma olduğunu AEB'de kurulan ilişkiler sisteminin uzlaşma elde edilmesine izin vermesi anlamında ideal olduğunu iddia etmiştir (Drujinin, 2020).

Her halükarda, entegrasyon projeleri; üyeleri için güvenli ve çekici bir ekonomik ve sosyal alan yaratmaya, onların varlıklarını ve kimliklerini korumalarına izin vermelidir. Bölgesel entegrasyon kendi başına bir amaç değildir. Artan rekabet ve kaynaklar için mücadele karşısında güçlü bir hayatta kalma yöntemi ve devletler/bölgeler hiyerarşisinde en iyi pozisyonları kazanmak için bir araçtır (Butorina \& Zaharov, 2014). Yine de hem tarihsel olarak hem de jeopolitik gereği nüfusu, yüzölçümü, ekonomisi ve kaynaklarıyla Rusya'nın AEB' de yönlendirici konumda olmasını doğal karşılamak gerekir.

\section{AVRASYA EKONOMIK BİRLİĞİ, SOVYETLER BİRLİĞI'NINN GERİ DÖNÜŞÜ ANLAMINA MI GELIYOR?}

Henüz Aralık 2012' de AEB'nin oluşum süreci devam ederken dönemin ABD Dişişleri Bakanı Hillary Clinton, Rusya'nın SSCB'yi yeniden canlandırmaya çalıştığını söyledi. Gümrük Birliği ya da Avrasya Birliği adı altında bölgenin Sovyetleşmesini istemediklerini, süreci yavaşlatmak veya durdurmak için etkili yollar geliştirmeye çalıştıklarını ifade etti ("Klinton: SŞA ne Dopustyat Vozrojdeniya SSSR", 2012). Batı kamuoyu, AEB yürürlüğe girdiğinde bunu Rusya'nın eski Sovyetler Birliği topraklarında tek bir siyasi ve ekonomik alan yaratma hamlesi, "SSCB'ye geri dönüş projesi" olarak algıladı. 2013 sonu 2014 başında yaşanan Ukrayna krizi, ABD ve AB'nin Ukrayna'yı "Rusya'dan kurtarıp" Batı kampına çekmeye çalışması, Rusya'ya Kırım'ın ilhakından dolayı ekonomik yaptırımlar uygulaması bir anlamda Avrasya'daki bu oluşumun önüne taş koyma çabalarıydı ("Yevraziyskiy Ekonomiçeskiy Soyuz: Vozvraşçeniye k SSSR?", 2015).

Avrasya bölgesinden gelen bazı söylemler de AEB'nin SSCB'yi canlandırma girişimi olduğuna ilişkin iddianın biraz daha yüksek sesle ifade edilmesini sağladı. Örneğin, Nisan 2005'te Putin, SSCB'nin yıkılışını “en büyük jeopolitik felaket olarak" nitelemiş, Mart 2018' de de Rus tarihinde hangi olayı değiştirmek istediği sorusuna net bir şekilde "Sovyetler Birliği'nin çöküşü" diye cevap vermişti ("Putin: If He Could, He'd Try to Prevent 1991 USSR Collapse", 2018). Belarus Devlet Başkanı Aleksandr Lukaşenko da Ekim 2019'da Kazakistan'a resmi ziyareti öncesi verdiği röportajda "Sovyetler Birliği'nde yaşıyorduk. Kesinlikle sıkı bir entegrasyon vard1... Yıkılanı yeniden yaratmak gerekiyor. Bunun üzerinde çalışmalıyız." şeklinde bir demeçte bulunmuştu (Drujinin, 2019). Doğal olarak bölgedeki komünistler SSCB'ye büyük bir özlem duyuyordu. Hükümet dışı bir siyasi parti olan Ermenistan Komünist Partisi'nin lideri Tachat Sargsyan ise bu özlemi açıça dile getirenlerin başında geliyordu. AEB'yi, SSCB'nin kuruluş sürecini başlatacak bir araç olarak görüyor, komünistlerin iktidarda olacağı SSCB'nin restorasyonu için bir fırsat yaratacağına inaniyordu (Bulgadaryan, 2014).

Açıkçası bu söylemlerden veya düşüncelerden SSCB'nin yeniden kurulacağı sonucunu çıkarmak hayalcilik olur. AEB'nin SSCB'ye dönüşme ya da yeni SSCB olma gibi bir niyeti yoktur. Daha en başta Hillary Clinton'a cevaben Rusya Devlet Başkanı Putin'in basın sözcüsü Dmitriy Peskov, eski SSCB topraklarında görülen şeyin yalnızca ekonomik 
entegrasyona dayalı bir oluşum olduğunu ve günümüz dünyasında başka türlü bir yapılanmanın mümkün olmadığını, ABD'nin Rusya'da ve eski SSCB ülkelerinde ortaya çıkan gelişmeleri "tamamen yanlış anladığını" söylemiştir. ("Klinton: SŞA ne Dopustyat Vozrojdeniya SSSR", 2012). Haziran 2014'te Kazakistan'ın Kızılorda eyaletinde düzenlenen Kazakistan-Rusya-Belarus uzman forumunda konuşan Kızılorda Valisi (günümüzde Kazakistan Devlet Sekreteri) Krımbek Kuşerbayev, ekonomik birliğin (AEB) 21. yüzyılda uygulanan ilk büyük ölçekli girişim olduğunu, bunu SSCB'nin canlanması olarak görenlerin halklarımızın tarihini, kültürünü ve zihniyetini anlamadığını belirtmiştir ("Yevraziyskiy Ekonomiçeskiy Soyuz Ne SSSR", 2014). Batı' daki SSCB canlanıyor mu kuşkusunu/endişesini entegrasyonun fikir babası Nursultan Nazarbayev ${ }^{3}$ de gidermeye çalışmıştır. Kasım 2016'da, Avrupa'daki Rusya'nın SSCB'yi bir araya getirmek istediği tartışmalarını/söylentilerini "saçmalık" olarak nitelemiş, AEB'nin tamamen ekonomik bir birlik niteliği taşıdığını, Soğuk Savaş'ta SSCB'nin yenilgisinin rövanşı olarak sunulması girişimini küresel rekabet ortamında oluşturulan bir algı olduğunu ifade etmiştir (Mamırbayeva, 2017; Belyakov, 2016). Benzer şekilde, Haziran 2019'da dönemin Avrasya Ekonomik Komisyonu Yönetim Kurulu Başkanı Tigran Sargsyan, AEB'yi Kremlin'in SSCB'yi yeniden kurma projesi olarak damgalayanların Birliğin özü hakkında hiçbir şey bilmediklerini iddia etmiştir. Ayrıca AEB'de eşit temsil ilkesine dayalı her üyenin veto hakkı olduğunu ifade etmiştir ("V YeEK Zaverili, Çto Yevraziyskiy Soyuz Ne Yavlyayetsya Proyektom Rossii Po Vostanovleniyu SSSR", 2019). Putin ise Nisan 2020'de, bölgede toplumlar arası tarihsel ve kültürel yakınlığın avantajını kullandıklarını, çabaların bir araya getirilmesinin herkesin yararına olduğunu belirterek, Batılıların SSCB tepkisinin nedeninin AEB ülkelerinin ekonomik yeteneklerinin artacağ 1 endişesi olduğunu ifade etmiştir (Drujinin, 2020). Bir başka deyişle, Putin'e göre Batılılar, kendi ekonomik çıarlarına ve halihazırda var olan dünya düzenine rakip oluşturacak bir oluşum istememektedir ve bunun için AEB'ye "olumsuz bir imaj" yüklemeye çalışmaktadır (Mamırbayeva, 2017).

Bütün bunlardan önce belki söylenmesi gereken şey; SSCB'nin bir işçi sınıfı devleti olduğudur. SSCB, burjuva iktidara sahip kapitalist bir devlet değildi. Piyasa ekonomisi ilkeleriyle değil sosyalist ilkelere sahip merkezi planlamayla yönetiliyordu. Bu bağlamda AEB'nin SSCB'ye dönüşmesi için öncelikle sosyalist bir devrim gerekmektedir. SSCB'nin yeniden kurulmasından kastedilen eski SSCB topraklarında siyasi bir birliğin kurulması

3 Nazarbayev, Ekim 2013'te Türkiye Cumhurbaşkanının kendisine gümrük birliğine girme talebinde bulunduğunu belirtmiş, bunu olumlu karşılamış ve Türkiye'nin üyeliğinin SSCB'nin yeniden kurulduğu dedikodularını da ortadan kaldıracağını ifade etmiştir (“Nursultan Nazarbayev Predlojil Prinyat Turtsiyu v TS!”, 2013). Siyaset bilimci, Rus milletvekili Sergey Markov da Ocak 2015'te Türkiye'nin AB yerine AEB'ye katılmas1 gerektiğini söylemiştir (Kozak, 2015). Ağustos 2016'da Türkiye Ekonomi Bakanı Nihat Zeybekçi Türkiye'nin AEB'ye girmeyi hedeflediğini söylese de ("Zeybekci: Avrasya Gümrük Birliği'ne Girme Hedefimiz Tekrar Gündemde", 2016), gerek AEB üyesi Ermenistan'la ilişkilerin bozuk olması gerekse de Türkiye'nin $\mathrm{AB}$ Gümrük Birliği'nde yer almasından kaynaklı ortaya çıkacak hukuki ve siyasi sorunlardan dolayı AEB üyeliği zor görünmektedir (Karluk, 2015). 
ihtimaliyse, Birlik bu konuda da herhangi bir emare göstermemektedir. Siyasi birlik meydana getirmek kolay bir şey değildir. Örneğin kuruluşu 1950'lere uzanan AB henüz tam anlamıyla bir siyasi birlik oluşturamadığı gibi üye devletlerden Birleşik Krallık'ı kaybetmiştir.

AEB, siyasi birlik oluşturmaktan ziyade böyle bir niyeti olmadığına dair emareler göstermektedir. Bununla ilgili olarak üç örnek verilebilir. Birincisi, 2013-2014 Ukrayna krizi sürecinde Rusya ile AEB'nin diğer üyeleri arasında bir dayanışma görülmedi, ilkesel olarak bu sorun Rusya-Ukrayna ve Rusya-Batı arasında bir sorun olarak değerlendirildi. $\mathrm{Bu}$ noktada, AEB üyesi ülkeler arasında bir siyasi güven eksikliğinden söz edilebilir (Kondakova, 2020). İkincisi, yukarıda da bahsedilen, AEB'nin 2025 yılı stratejik hedefleriyle ilgili olarak Kazakistan önemli bir noktaya dikkat çekti. Mayıs 2020'de Devlet Başkanı Kasım Cömert Tokayev; sağlık, eğitim ve bilim gibi alanlara dair konuların bütünüyle Avrasya Ekonomik Komisyonu'nun yetkisine verilmesini Birliğin ekonomik yönünü temelden değiştirebileceği endişesini dile getirdi. 2025 hedefleri Yüksek Avrasya Ekonomik Konseyi'nde kabul edilse de Kazakistan ileride siyasi birlik kurma niyetinde olmadığını üstü kapalı bir şekilde kamuoyuna göstermiş oldu ("Prezident Kasım-Jomart Tokayev Prinyal Uçastiye v Zasedanii Vısşego Yevraziyskogo Ekonomiçeskogo Soveta", 2020). Üçüncüsü, Eylül-Kasım 2020'de Azerbaycan ile Ermenistan arasında yaşanan Dağlık Karabağ Savaşı'nda Rusya kesinlikle AEB üyesi Ermenistan'ın yanında yer almadı. Tarafsız bir pozisyon aldı, savaşın Azerbaycan lehine ilerlemesinden, Ermenistan'ın yenilgisinden rahatsız olmadi ${ }^{4}$. Savaş sonunda arabulucu olarak iki ülke arasında barış antlaşması imzalanmasını sağladı.

Netice itibariyle, bağımsızlıklarını kazanmalarının üzerinden henüz 30 yıl geçmiş devletlerin ne SSCB'yi tekrar canlandırma ne de siyasi birlik oluşturma niyetleri vardır.

\section{SONUÇ}

AEB, dünyada şu an yürürlükte bulunan gümrük birliği ve serbest ticaret alanı temelinde kurulmuş birliklerden biridir. Dünyanın herhangi bir bölgesinde ekonomik birlik nasıl değerlendirilirse AEB de öyle değerlendirilmelidir. Uluslararası alanda çok sayıda ekonomik birlik vardır. Muhtemelen hiçbiri Avrasya halklarının geçmişte yaşadığı tecrübeye ve yakınlığa sahip değildir. Avrasya bölgesi, uzun süre beraber yaşamış, ortak tarih, dil, kültür ve geleneklere sahip olmuş ülkelerin bulunduğu bir coğrafyadır. Bu bağlamda AEB'nin kurulması son derece olağan bir gelişmedir ve hiç kimse için şaşırtıcı olmaması gerekir. Ama ekonomik ve siyasi olarak uluslararası alandaki benzerlerinden daha fazla ilgi çekmektedir. Bunun üç sebebi vardır. Birincisi, AEB'nin Avrasya kavramını kullanması ve Avrasyacılık mantalitesine sahip olmasıdır. İkincisi, üyelerinden birinin Batı dünyasıyla tarihsel olarak (özellikle kabaca son 100 yıl içerisinde) iyi geçinemeyen Rusya'nın olmasıdır. Üçüncüsü, ise, Avrasya bölgesinin Batı'nın siyasi ve ekonomik yayılma alanı içerisinde yer almasıdır. Rusya, Avrasyacı yaklaşıma uygun bir şekilde bölgede Batı'nın etkinliğine karşı duvar

\footnotetext{
${ }^{4}$ Rusya'nın bu politikasının sebebi olarak, Azerbaycan'la son derece iyi olan ilişkilerini bozmak istememesi ve Ermenistan Başbakanı Nikol Paşinyan'ın Avrasyacı anlayıştan ziyade Batı'yla yakın ilişkiler kurmak isteyen liberal bir perspektife sahip olması söylenebilir (Baunov, 2020).
} 
oluşturmakta; büyük, saygın ve güçlü bir devlet olarak küresel dünyada yerini sağlamlaştırmak istemektedir. Batı, AEB'nin varlığından memnun değildir. Rusya'nın, bölgesinde diğer ülkelerle dostluklar kurup siyasi/ekonomik açıdan etkili/nüfuz sahibi olmasını istememektedir. Birliği, SSCB'nin geri dönüşü şeklinde değerlendirmekte hatta Avrasya bölgesinde de böyle bir algının oluşmasını arzu etmektedir. Böylelikle bölge ülkelerinde burjuva sınıfların ve Sovyet karşıtı liberallerin AEB'nin gelişimini olumsuz etkileyecek bir tavır takınmaların beklemektedir. AEB ise, $A B D$ ve $A B$ etkisinden bağımsız bir alan yaratmaya çalışırken bunu Batı'ya karşı düşmanlık sloganlarıyla yapmamakta, bilakis onlarla işbirliğine açık olduğunu vurgulamaktadır.

\section{Araştırmacıların Çatışma Beyanı / Researchers'Conflict of Interest Statement}

Yazarlar, bu çalışmada potansiyel bir çıkar çatışması olmadığını beyan etmişlerdir. The authors declare that there is no potential conflict of interest in this study.

\section{KAYNAKÇA}

Apokin, A. Yu. (2021, Mart 15). Bolşaya Rossiyskogo Entsiklopediya, Yevraziyskiy Ekonomiçeskiy Soyuz. Bigenc.ru. İndirilme Tarihi: 15 Mart 2021, URL: https://bigenc.ru/geography/text/5868052

Bassin, M. (2011). 'Klasik' ve 'yeni' avrasyacılık: Geçmişten gelen devamlılık. Çev. Ö. Tüfekçi. Bilge Strateji, 2(4), 117-135.

Baunov, A. (2020, Ekim 8). V Ojidanii Soyuznikov. Poçemu Rossiya Ne Speşit Pomogat Armenii v Karabahe. Carnegie.ru. İndirilme Tarihi: 15 Mart 2021, URL: https://carnegie.ru/commentary/82921

Bekcan, U. (2013). Yeni Dünya Düzeninde Rusya-Çin İlişkileri. Ankara: Phoenix Yayınları.

Belyakov, I. (2016, Kasım 25). Nazarbayev: Rossiya ne Pitayetsya Vıstroit İz YeAES Noviy SSSR. Rg.ru. İndirilme Tarihi: 15 Mart 2021, URL: https://rg.ru/2016/11/25/nazarbaevrossiia-ne-pytaetsia-vystroit-iz-eaes-novyj-sssr.html

Bulgadaryan, N. (2014, Kasım 30). Armyanskiye Kommunistı Ubejdenı, Çto YeAES Budet Sposobstvovat Vosstanovleniyu Sovetskogo Soyuza. Radio Azatutyun. İndirilme Tarihi: 15 Mart 2021, URL: https://rus.azatutyun.am/a/26717336.html

Butorina, O. \& Zaharov, A. (2014, Ağustos 6). Yevraziyskiy Ekonomiçeskiy Soyuz: Çto Dalşe. Vedomosti.ru. İndirilme Tarihi: 15 Mart 2021, URL: https://www.vedomosti.ru/opinion/articles/2014/08/06/evrazijskij-ekonomicheskijsoyuz-chto-dalshe

Drujinin, A. (2019, Ekim 23). Lukaşenko Predlojil İspolzovat v YeAES Opıt “Tesnoy İntegratsii" SSSR. Ria.ru. İndirilme Tarihi: 15 Mart 2021, URL: https://ria.ru/20191023/1560135529.html

Drujinin, A. (2020, Nisan 19). Putin Zayavil, Çto Postsovetskiye Stranı Postepenno Preodolevayut Strahi Vozrojdeniya SSSR. Tass.ru. İndirilme Tarihi: 15 Mart 2021, URL: https://tass.ru/politika/8281131 
Dugin, A. (2002). Osnovı Yevraziystva. Moskva, Rossiya: Arktogeya Tsentr.

Dugin, A. (2003). Rus Jeopolitiği ve Avrasyacı Yaklaşım. İstanbul: Küre Yayınları.

Hronologiya Razvitiya. (2021, Mart 15). Eaeunion.org. İndirilme Tarihi: 15 Mart 2021, URL: http://www.eaeunion.org/?lang=ru\#about-history

Karluk, S. R. (2015). Avrasya Gümrük Birliği ve Türkiye'nin Üyeliği. İndirilme Tarihi: 15 Mart 2021, URL: http://avekon.org/papers/1343.pdf

Kirgiziya ne Podpisala Zayavleniye o Razvitii Torgovli v YAES. (2016, Aralık 26). Vedomosti.ru. İndirilme Tarihi: 15 Mart 2021, URL: https://www.vedomosti.ru/politics/news/2016/12/26/671291-kirgiziya-ne-podpisala

Klinton: SŞA ne Dopustyat Vozrojdeniya SSSR. (2012, Aralık 7). Rt.com. İndirilme Tarihi: 15 Mart 2021, URL: https://russian.rt.com/article/1787

Kondakova, Ye. (2020, Mayıs 21). Mejdu ES i SSSR. Ekspertı Obyasnili, Çto İz Sebya Predstavlyayet Yevraziyskiy Soyuz. Ukraina.ru. İndirilme Tarihi: 15 Mart 2021, URL: https://ukraina.ru/exclusive/20200521/1027755478.html

Kozak, M. (2015, Ocak 13). Rus Sözcü Markov: Türkiye AB’ye değil, Avrasya Birliği'ne Katılmalı. Günhaber.com. İndirilme Tarihi: 15 Mart 2021, URL: http://www.gunhaber.com.tr/haber/Rus-sozcu-Markov-Turkiye-AB-ye-degilAvrasya-Birligi-ne-katilmali/381583

Mamırbayeva, Yu. (2017, Mart 29). Razruşayem Mifı: Top-7 Tipiçnıh Zablujdeniy o YeAES. Russiancouncil.ru. İndirilme Tarihi: 15 Mart 2021, URL: https://russiancouncil.ru/analytics-and-comments/analytics/razrushaem-mify-top-7tipichnykh-zabluzhdeniy-o-eaes/

Nursultan Nazarbayev Predlojil Prinyat Turtsiyu v TS!. (2013, Ekim 25). Web.archive.org. $\begin{array}{llll}\text { Indirilme } & \text { Tarihi: } & 15 & \text { Mart 2021, URL: }\end{array}$ http://web.archive.org/web/20131231001230/http://z001.kz/news/view?id=13020

Organı Upravleniya. (2021, Mart 15). Eaeunion.org. İndirilme Tarihi: 15 Mart 2021, URL: http://www.eaeunion.org/?lang=ru\#about-administration

Prezident Kasım-Jomart Tokayev Prinyal Uçastiye v Zasedanii Vısşego Yevraziyskogo Ekonomiçeskogo Soveta. (2020, Mayıs 19). Akorda.kz. İndirilme Tarihi: 15 Mart 2021, URL:

https://www.akorda.kz/ru/events/international_community/foreign_other_events/pre zident-kasym-zhomart-tokaev-prinyal-uchastie-v-zasedanii-vysshego-evraziiskogoekonomicheskogo-soveta

Putin: If He Could, He'd Try to Prevent 1991 USSR Collapse. (2018, Mart 2). Apnews.com. İndirilme Tarihi: 15 Mart 2021, URL: https://apnews.com/article/d36b368c6ad44bb2b8e883fc8d800514

Schaffner, T. (2019, Eylül 26). John Mearsheimer on Russia: Insights and Recommendations. Russiamatters.org. İndirilme Tarihi: 15 Mart 2021, URL: https://www.russiamatters.org/analysis/john-mearsheimer-russia-insights-andrecommendations 
Tolz, V. (1998). Conflicting 'homeland myths' and nation-state building in postcommunist Russia. Slavic Review, (57)2, 267-294.

Tsoy, D. (2016, Haziran 15). Buduşee v Sozdanii Obşego Prostranstva Ot Atlantiki Do Tihogo Okeana. İzvestiya.ru. İndirilme Tarihi: 15 Mart 2021, URL: https://iz.ru/news/618130

V YeEK Zaverili, Çto Yevraziyskiy Soyuz Ne Yavlyayetsya Proyektom Rossii Po Vostanovleniyu SSSR. (2019, Haziran 7). Knews.kg. İndirilme Tarihi: 15 Mart 2021, URL: $\quad$ https://knews.kg/2019/06/07/v-eek-zaverili-chto-evrazijskij-soyuz-neyavlyaetsya-proektom-rossii-po-vosstanovleniyu-sssr/

Vinokurov, Ye. Yu., Korşunov, D. A., Pereboyev, V. S., Tsukarev, T. V. (2017). Yevraziyskiy Ekonomiçeskiy Soyuz. Sankt Peterburg, Rossiya: Tsiİ YeABR.

Vısşiy Yevraziyskiy Ekonomiçeskiy Sovet. (2020). O Strategiçeskih Napravleniyah Ravitiyiya Yevraziyskoy Ekonomiçeskoy İntegratsii Do 2025 Goda. Minsk; İndirilme Tarihi: 15 Mart 2021, URL: https://docs.eaeunion.org/docs/ru-ru/01228321/err_12012021_12

Yevraziyskiy Ekonomiçeskiy Soyuz Ne SSSR. (2014, Haziran 14). Kapital.kz. İndirilme Tarihi: 15 Mart 2021, URL: https://kapital.kz/gosudarstvo/30944/yevraziyskiyekonomicheskiy-soyuz-ne-sssr.html

Yevraziyskiy Ekonomiçeskiy Soyuz: Vozvraşçeniye k SSSR?. (2015, Ocak 5). Russian.people.com. Indirilme Tarihi: 15 Mart 2021, URL: http://russian.people.com.cn/n/2015/0105/c95181-8831602.html

Zeybekci: Avrasya Gümrük Birliği'ne Girme Hedefimiz Tekrar Gündemde. (2016, Ağustos 23). Tr.sputniknews.com. İndirilme Tarihi: 15 Mart 2021, URL: https://tr.sputniknews.com/turkiye/201608231024512810-zeybekci-avrasya-gumrukbirligi-hedefimiz-gundemde/ 